\title{
Review
}

\section{Rationale for Different Approaches to Combined Melphalan and Hyperthermia in Regional Isolated Perfusion}

\author{
J. van der Zee, ${ }^{1}$ B.B.R. Kroon, ${ }^{2}$ O.E. Nieweg, ${ }^{2}$ S.A. van de Merwe ${ }^{1}$ and H.H. Kampinga ${ }^{3}$ \\ 'Department of Hyperthermia, University Hospital Rotterdam/Dr Daniel den Hoed Cancer Center, Groene \\ Hilledijk 301, 3075 EA, Rotterdam; 'Department of Surgery, The Netherlands Cancer Institute (Antoni van \\ Leeuwenhoek Huis), Amsterdam; and ${ }^{3}$ Department of Radiobiology, University of Groningen, \\ The Netherlands
}

The addition of hyperthermia (HT) to regional isolated perfusion (RIP) with Melphalan theoretically has two advantages. Firstly, heat can selectively kill cells in poorly vascularised areas that are usually not reached by the drug. Secondly, in vitro data have revealed that the effect of Melphalan is enhanced at temperatures $39-45^{\circ} \mathrm{C}$. However, for the simultaneuus application of Melphalan and HT, as it is given in most institutes, both normal and tumour tissues within the volume are treated with both modalities. It is unclear whether-for the same heat dose-the cytoxicity of Melphalan is enhanced more in tumour tissue than in normal tissues. As the applied dose of Melphalan in RIP is selected on maximum acceptable toxicity, any enhancement of toxicity is undesired. Indeed, Melphalan application at temperatures $>41^{\circ} \mathrm{C}$ has resulted in unacceptable toxicity. In most institutes, the hyperthermia dose is reduced in comparison to application as a single-modality treatment, to allow simultaneous combination without unacceptable toxicity. In this review, the rationale for two different approaches is summarised which may make it possible to improve the benefit from the theoretical advantage of the use of HT in RIP. It is meant to stimulate discussion as a possible first step in the design of new treatment protocols. (C) 1997 Elsevier Science Ltd.

Key words: hyperthermia, malignant melanoma, melphalan, regional isolated perfusion Eur f Cancer, Vol. 33, No. 10, pp. 1546-1550, 1997

\section{INTRODUCTION}

REGIONAL ISOLATED perfusion (RIP) with Melphalan and hyperthermia (HT) is a generally accepted treatment for locally or regionally advanced melanoma of an extremity. However, the role of HT in RIP with Melphalan, and the optimum schedule for combining the two modalities, are not well defined. Reports of better results from current HT pertusions in comparison with those from earlier studies may have to be explained by the fact that in those early days no special measures were taken to prevent the limb from cooling down during preparative surgery. Tissue temperatures of the limb were probably as low as $30^{\circ} \mathrm{C}[1]$. In view of this, the comparison is between hyper- and hypothermia, a condition which probably interferes with the

Correspondence to J. van der Zee.

Received 2 Oct. 1996; revised 17 Fcb. 1997; accepted 28 Feb. 1997. exposure of tumour cells to chemotherapy. This background is the reason that the members of the 'AmRo perfusion team', a co-operative group from both the Dr Daniel den Hoed Cancer Center in Rotterdam and The Netherlands Cancer Institute in Amsterdam, have chosen to apply RIP with Melphalan at controlled normothermic $\left(37-38^{\circ} \mathrm{C}\right)$ temperatures [2].

However, HT is an interesting modality in the treatment of cancer. Recently, the therapeutic gain by HT in addition to radiotherapy, was proven by randomised comparative studies for various types of tumour [3-6]. Both experimental and clinical data indicate that the application of HT results in tumour cell kill at dose levels which are not toxic to normal tissues. HT is especially toxic to cells in insufficiently perfused areas of tumours, which are hypoxic and acidic $[7,8]$. HT has a greater effect on tumour tissue than on normal tissue due to the indirect effects of inducing vascular stasis. Such vascular stasis is caused by heat damage 
to endothelial cells; up to a certain HT dose level, the high proliferation rate of endothelial cells in tumours renders them more sensitive to HT than 'normal' endothelial cells that have slower proliferation rates [9]. Unfortunately, (heat-induced) stasis may also have a counteracting effect as it will lead to reduced drug penetration in insufficiently perfused areas. Moreover, HT may also enhance drug toxicity to normal tissues. When Melphalan is applied at the dose which is maximally tolerable in normothermic RIP, this leads to unacceptable toxicity, as was indeed found to be true in some clinical trials (see Section Clinical data).

Two different approaches to circumvent the problem of thermal enhancement of normal tissue toxicity are suggested. The first is to use only the complementary action of heat (specific killing of drug-resistant cells in poorly vascularised areas) by sequential application in two RIP treatments with a one week interval. The second is to reduce the drug dose in a simultaneous application and benefit from both the preferential effect that HT has on cells in poorly perfused areas and the enhancement of drug cytotoxicity.

\section{EFFECT OF COMBINED MELPHALAN AND HYPERTHERMIA}

\section{Preclinical data}

Experimental data have shown that the cytotoxicity of Melphalan increases with higher temperatures, beginning at temperatures as mild as $39-40^{\circ} \mathrm{C}[10,11]$. Thermal enhancement was found to be rapidly lost with an increasing time interval between the two treatments [10].

In cancer treatment, it is important to achieve a therapeutic gain, i.e. more enhancement of cytotoxicity to the tumour tissue compared to normal tissues. There is only limited information concerning therapeutic gain with regard to simultaneous combination of Melphalan and HT. For simultaneous combination of Melphalan and whole body HT (45 min at $41^{\circ} \mathrm{C}$ using a rat model), the thermal enhancement ratio (TER; defined as the ratio of the drug dose required to produce a certain biological effect and the drug dose which in combination with HT leads to the same effect) for tumour growth delay varied from 2 to 4.3 [12]. For bone marrow toxicity, the TER varied from 1.7 to 2.9 . In a study in dogs with spontaneous malignant melanoma, whole body HT of $60 \mathrm{~min}$ at $41.9-42^{\circ} \mathrm{C}$ enhanced the probability of severe haematological toxicity from Melphalan with a factor of 1.9 , whereas no improvement in tumour response was found in the combined treated group [13]. These results emphasise that normal tissue toxicity is exacerbated by simultaneous application of Melphalan and
HT. Since the relatively mild HT temperature do not induce such effects in normal tissue when applied as a single treatment (see below), it must be concluded that these are the result of thermal enhancement of drug toxicity. A therapeutic gain is not achieved as a rule by the simultaneous combination of whole body HT and systemic application of Melphalan. Similar types of problems may also be encountered when using RIP, but this has not been tested in animals.

\section{Clinical data}

Clinical data indicate that simultaneous combination of high doses of Melphalan and HT results in unacceptable toxicity. Whereas Vaglini and associates, in their early studies [14], administered Melphalan at tissue temperatures of $42.5-43^{\circ} \mathrm{C}$, they later reported that the temperature should be below $41.5^{\circ} \mathrm{C}$ to avoid too severe complications [15]. As revealed by a logistic regression model of a series of patients treated with RIP in Amsterdam and Rotterdam [16], one of the factors associated with more severe toxicity was tissuc temperature of $40^{\circ} \mathrm{C}$ or higher. The AmRo perfusion group applied simultaneous $\mathrm{HT}\left(41-42^{\circ} \mathrm{C}\right)$ and Melphalan to 11 patients with malignant melanoma. Melphalan was added slowly (over 1 circulation time) to the perfusate when the tissue temperatures had reached $41^{\circ} \mathrm{C}$. The Melphalan dose was $10 \mathrm{mg} / 1$ perfused tissue for leg perfusions and $13 \mathrm{mg} / 1$ for arm perfusions. The toxicity of this regimen was unacceptably severe [17]. In 1 patient, amputation was unavoidable after development of a compartmental syndrome and tissue necrosis. In 5 patients, irreversible functional impairment of the treated limb resulted, due to paralysis of the peroneal nerve and/or fibrosis or ankylosis.

Generally, however, severe toxicity following hyperthermic RIP occurs less frequently. In 2966 treated patients, overall functional impairment of the limb occurred in $4.2 \%$ of the patients and amputation was necessary in $0-6 \%$ (overall $1 \%$ ) of the patients (Cavaliere and associates [18]). The only publication reporting amputation in $6 \%$ is that by Vaglini and associates [14] on perfusion at tissue temperatures of $42.5-43^{\circ} \mathrm{C}$. The higher toxicity in our own study, compared to other published results, was suggested to be due to the high tissue temperatures at the time of Melphalan administration [17]. From other reports, it can be derived that the level of similar high temperatures is reached only in the course of the cytostatic perfusion. By that time, the Melphalan concentration has already decreased by $40-45 \%$, leaving less drug available for thermal enhancement of drug cytotoxicity.

Table 1. Regional isolated perfusion: complete response rates reported for melanoma

\begin{tabular}{lccc}
\hline Reference & CRs $n$ & $\%$ & $\begin{array}{c}\text { Tissue } \\
\text { temperature }\end{array}$ \\
\hline Kroon and associates [20] & $7 / 18$ & 39 & $37-38 \mathrm{C}$ \\
Kroon and associates [25] (two normothermic RIPs) & $33 / 43$ & 77 & $37-38 \mathrm{C}$ \\
Rosin and Westbury [21] & $21 / 80$ & 26 & $39-40^{\circ} \mathrm{C}$ \\
Lejeune and associates [22] & $15 / 23$ & 65 & $39-41 \mathrm{C}$ \\
Vaglini and associates [15] & $18 / 32$ & 56 & $40-41 \mathrm{C}$ \\
Storm and Morton [23] & $21 / 26$ & 81 & $40-41.8 \%$ \\
Di Filippo and associates [24] & $27 / 69$ & 39 & $41-42 \mathrm{C}$ \\
Kroon and associates [17] & $7 / 11$ & 64 & $41-42 \mathrm{C}$ \\
Kroon and associates [19] (sequential application) & $9 / 10$ & 90 & $42-43 \mathrm{C}$ \\
\hline
\end{tabular}


Table 2. Normal tissue tolerance to hyperthermia

\begin{tabular}{|c|c|c|c|c|}
\hline \multirow[b]{2}{*}{ Tissue type } & \multicolumn{3}{|c|}{ Dose } & \multirow[b]{2}{*}{ Damage } \\
\hline & Species & Time (min) & Temp. (C) & \\
\hline \multirow[t]{4}{*}{ Skin } & mouse $[27]$ & 60 & 43 & none \\
\hline & mouse [28] & 15 & 44 & oedema, recovered in 2 days \\
\hline & pig [29] & 150 & 45 & mild hyperaemia \\
\hline & human [29] & 120 & 45 & hyperaemia \\
\hline Subcutaneous fat & pig $[30]$ & 30 & 45 & mild changes \\
\hline \multirow[t]{2}{*}{ Muscle } & pig โ30] & 30 & 45 & mild changes \\
\hline & pig [31] & $20-40$ & 47 & minimum \\
\hline \multirow[t]{3}{*}{ Nerve } & rat [32] & 30 & 43 & none \\
\hline & rat $[33]$ & 37.5 & 43 & mild, recovered in 4 weeks \\
\hline & $\operatorname{dog}[34,35]$ & 60 & $43-44$ & mild, recovered in 3 weeks \\
\hline Lymph node & rat $[36]$ & 30 & 45 & minimum \\
\hline Whole limb & $\operatorname{dog}[37]$ & 120 & $42-44$ & no major damage \\
\hline
\end{tabular}

In Table 1, published complete response rates following RIP are summarised [15, 17, 19-25]. Overall, complete response rates achieved with perfusion at tissue temperatures of $\geqslant 40^{\circ} \mathrm{C}$ range from 36 to $81 \%$. The $39 \%$ complete response rate following normothermic RIP reported by Kroon and associates [20] is not significantly lower than that produced by most of the mild $\left(39-40^{\circ} \mathrm{C}\right)$ or true $\left(41-42^{\circ} \mathrm{C}\right)$ hyperthermic RIPs. In only one publication, a significant higher complete response rate was reported [23]. Following a schedule applying two separate normothermic RIPs with Melphalan, a complete response rate of $77 \%$ was achieved [25]. The simultaneous administration of 'true' HT as applied by Kroon and associates [17] resulted in a $64 \%$ complete response rate, but, as mentioned before, this treatment regimen was discontinued because of unacceptable toxicity.

Limb recurrence-free intervals and overall survival were compared retrospectively for two groups of patients treated in The Netherlands and Belgium with either 'controlled normothermic' or 'mild' hyperthermic RIP following excision of tumour lesions. Controlling for a variety of prognostic factors, the application of 'mild' HT did not influence limb recurrence-free interval nor survival [26].

\section{NORMAL TISSUE TOLERANCE TO HYPERTHERMIA}

It is unlikely that the toxicity observed following 'true' hyperthermic Melphalan RIPs is due to the effect of heat alone. A summary of results on normal tissue tolerance to HT which are relevant for a limb is given in Table 2 [19, 27-37]. Skin, fat and muscle tissucs of a pig are not severely damaged by a heat dose of $30 \mathrm{~min}$ at $45^{\circ} \mathrm{C}$. This heat dose is equivalent to $120 \mathrm{~min}$ at $43^{\circ} \mathrm{C}$ [38]. Peripheral nervous tissue may be somewhat more sensitive to hyperthermia, but toxicity appears acceptable (rapidly reversible) for HT treatments up to $60 \mathrm{~min}$ at $44^{\circ} \mathrm{C}$. Limb perfusion in dogs was tolerated without irreversible damage up to a dose of $2 \mathrm{~h}$ at $42-44^{\circ} \mathrm{C}$ [37] and in humans an HT dose of $2 \mathrm{~h}$ at $42-$ $43^{\circ} \mathrm{C}$ without Melphalan was found to be safe, provided that pressure on the normal tissues was avoided, which otherwise might have caused normal tissue hypoxia [19].

\section{DOUBLE PERFUSIONS WITH SEQUENTIAL APPLICATION OF HEAT AND MELPHALAN: FIRST CLINICAL EXPERIENCE}

In order to avoid the risk of unacceptable normal tissue toxicity following simultaneous application of heat and Melphalan, but still benefit from the ability of heat to be complementary to Melphalan, sequential applications of high-dose HT $\left(2 \mathrm{~h}\right.$ at $42-43^{\circ} \mathrm{C}$ ) and Melphalan perfusion 1 week later has been applied to 10 patients with locally inoperable recurrent melanoma [19]. A complete response was achieved in 9 patients, whilst 1 patient showed a partial response. Impressive tumour regressions and central tumour necrosis were found in most of the patients within 1 week following HT perfusion; one example is given in Figure 1. The median duration of complete response was $5+(3+-12+)$ months. Two patients developed a recurrence in the perfused region, both after 5 months. The schedule was well tolerated with few side-effects. It can be deduced from these initial data that the extra perfusion with heat alone may lead to better tumour control than normothermic or 'mild' HT RIP with Melphalan (see Table 1). However, the major disadvantage of the sequential combination is that it requires two surgical procedures.

\section{MORE HEAT, LESS DRUG: AN ALTERNATIVE APPROACH}

Another approach, in which both the disadvantage of the two surgical procedures can be avoided and the advantage of optimum use of the two treatment modalities may be exploited, would be to administer HT at the maximum tolerated level, and reduce the simultaneously administered Melphalan dose on the basis of the maximum acceptable toxicity at that temperature. The only assumption made for this approach is that, for the same heat dose, the cytoxicity of Melphalan is equally enhanced in well-perfused tumour tissue compared to normal tissues. With this assumption, the biological rationale for the 'more heat-less drug approach' is as follows.

1. The normal tissue toxicity remains within acceptable levels, since the Melphalan dose is reduced according to the enhancement obtained by the simultaneous heat treatment. Such a new tolerance dose should be derived from phase I studies. Yet, it already has been suggested 


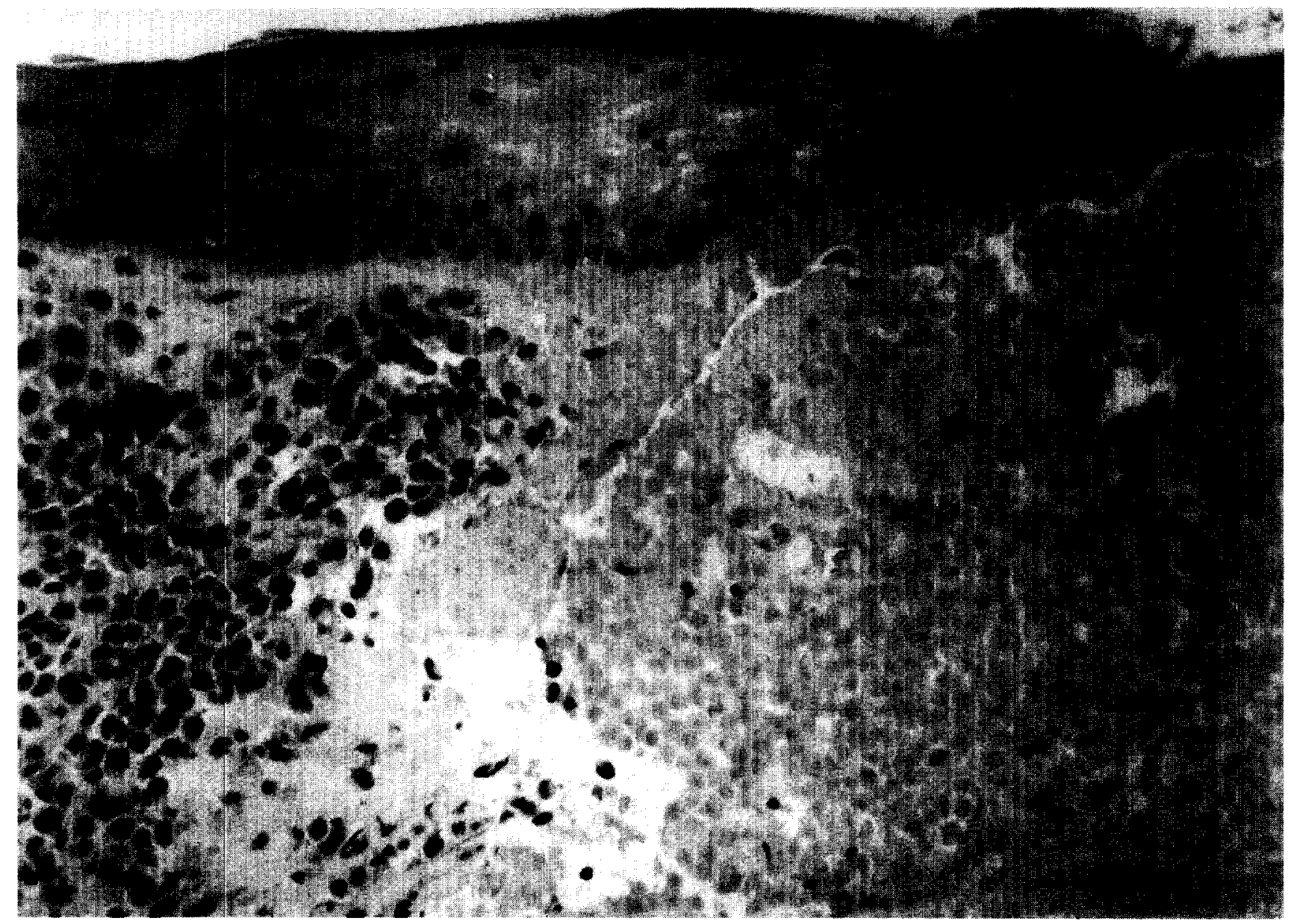

Figure 1. Histopathology of a tumour nodule excised immediately before perfusion of Melphalan, 1 week after RIP for $2 \mathrm{~h}$ at 42.5 $\mathrm{C}$ in a patient with multiple in transit metastases of malignant melanoma. The tumour centre has become necrotic, cells in the tumour periphery and the nearby skin are vital, demonstrating the preferential effect of HT in part of the tumour.

that the Melphalan dose to be given is $12 \mathrm{mg} / 1$ perfused tissue when tissue temperatures are increased to $41.5^{\circ} \mathrm{C}$ or higher, whereas it can be $14 \mathrm{mg} / 1$ perfused tissue at a temperature of $39^{\circ} \mathrm{C}[18]$.

2. As a consequence of our assumption, the antitumour efficacy of this approach in well-perfused tumour tissues is similar to that achieved with 'standard' application.

3. The main beneficial effect of this approach concerns the cells in insufficiently perfused parts of the tumour. In view of the experience with $\mathrm{HT}$ alone in the sequentially applied combination, an HT dose of $2 \mathrm{~h}$ at approximately $42.5^{\circ} \mathrm{C}$ is highly effective. Putative negative effects of HT-induced stasis [9] on drug penetrance, if occurring at all during treatment, are likely to be compensated for by the preferential heat kill of cells in these areas of vascular occlusion and by the drug sensitisation effect.

As both drug and heat cytotoxicity are used at 'full' capacity, that is, to the limits of tolerance, in theory this approach can be expected to give similar good responses compared to the sequential combination of HT and Melphalan.

\section{CONCLUSION}

The application of HT in perfusion falls into one of three categories: 'controlled normothermia' (tissue temperatures between 37 and $\left.38^{\circ} \mathrm{C}\right)$, 'mild' HT $\left(39-40^{\circ} \mathrm{C}\right)$ and 'true'
HT (41.5-43 C). 'Controlled normothermic' perfusion focuses on the effect of the cytostatic drug alone. 'Mild' HT may, to some extent, potentiate the cytostatic effect of Melphalan [12], although the clinical data do not support this notion. Perfusions with 'true' HT without alterations in scheduling or adaptations in drug dose lead to unacceptable toxicity due to heat and drug interaction. Yet, true HT is tolerable and may lead to better tumour control if applied separately from Melphalan. When the two treatment modalities are combined sequentially, both HT and Melphalan can be administered at optimum levels. True HT perfusion will kill cells in the hypoxic parts of the tumour, without causing normal tissue toxicity. The second normothermic perfusion with Melphalan will attack the residual well-perfused parts of the tumour. However, the need for two surgical procedures is a major disadvantage. As an alternative approach, it is suggested that a maximally tolerated HT treatment is applied simultaneously with a reduced dose of Melphalan. With the appropriate dose reduction (based on the enhancement factor for drug toxicity), this (a) should not compromise the cffcct of the drug in well-perfused tumour areas; (b) should not lead to an unacceptable toxicity in normal tissues; (c) maximally utilises the selective effect of HT in poorly perfused areas of the tumour; and (d) require only one surgical procedure. Such an approach deserves further attention. 
There should be discussion on this topic, since the simultaneous combination of Melphalan and HT in RIP as currently applied in most institutes may be far from optimal.

1. Stehlin JS. Hyperthermic perfusion with chemotherapy for cancers of the extremities. Surg Gynecol Obst 1969, 129, 305-308.

2. Wieberdink J. Physiological considerations regarding isolation perfusion of the extremizies. Monograph available from The Netherlands Cancer Institute, Amsterdam, Krips Repro Meppel, 1978.

3. Valdagni $R$, Amichetti $M$, Pani $G$. Radical radiation alone versus radical radiation plus microwave hyperthermia for $\mathrm{N} 3$ (TMN-UICC) neck nodes: a prospective randomized clinical trial. Int f Radiat Oncol Biol Phys 1988, 15, 13-24.

4. Overgaard J, Gonzalez Gonzalez D, Hulshof MCCM, et al. Randomised trial of hyperthermia as adjuvant to radiotherapy for recurrent or metastatic malignant melanoma. Lancet $1995,345,540-543$.

5. International Collaborative Hyperthermia Group. Hyperthermia in the treatment of superficial localized primary and recurrent breast cancer-results from five randomized controlled trials. Int 7 Radiat Oncol Biol Phys 1996, 35, 731-744.

6. Zee van der J, Gonzalez Gonzalez D, Rhoon van GC et al. Results of additional hyperthermia in inoperable pelvic tumours. In Franconi $\mathrm{C}$, Arcangeli $\mathrm{G}$, Cavaliere $\mathbf{R}$, eds. Hyperthermic Oncology. Rome, Tor Vergata Post Graduate School of Medical Physics, 1996, 215-217.

7. Field SB. In vivo aspects of hyperthermic oncology. In Field $\mathrm{SB}, \mathrm{Hand} \mathrm{JW}$, eds. An introduction to the practical aspects of clinical hyperthermia. London, Taylor and Francis, 1990, 55-68.

8. Raaphorst GP. Fundamental aspects of hyperthermic biology. In Field SB, Hand $\mathrm{JW}$ eds. An introduction to the practical aspects of clinical hyperthermia. London, Taylor and Francis, $1990,10-54$.

9. Reinhold HS, Berg van den AP. Effects of hyperthermia on blood flow and metabolism. In Field SB, Hand JW, eds. An introduction to the practical aspects of clinical hyperthermia. London, Taylor and Francis, 1990, 77-107.

10. Dahl $\mathbf{O}$. Interaction of heat and drugs in vitro and in vivo Seegenschmiedt MH, Fessenden P, Vernon CC, eds. Medical Radiology. Thermoradiotherapy and thermochemotherapy vol. I. Rerlin, Springer-Verlag, 1995, 103-121.

11. Bates DA, Mackillop WJ. The effect of hyperthermia on the uptake and cytotoxicity of Melphalan in Chinese Hamster ovary cells. Int f Radiat Oncol Biol Phys 1989, 16, 187-191.

12. Honess DJ, Bleehen NM. Thermochemotherapy with cis-platinum, CCNU, BCNU, chlorambucil and Melphalan on murine marrow and two tumours: therapeutic gain for Melphalan only. Br f Radiol 1985, 58, 63-72.

13. Page RL, Thrall DE, Dewhirst MW, et al. Phase I study of Melphalan alone and Melphalan plus whole body hyperthermia in dogs with malignant melanoma. Int $f$ Hyperthermia 1991, 7, 559-566.

14. Vaglini $M$, Ammatuna $M$, Nava $M$, et al. Regional perfusion at high temperature in treatment of stage IIA-IIIAB melanoma patients. Tumori $1983,69,585-588$.

15. Vaglini $M$, Andreola $S$, Attili $A$, et al. Hyperthermic antiblastic perfusion in the treatment of cancer of the extremities. Tumori $1985,71,355-359$.

16. Klaase JM, Kroon BBR, Geel van AN, Eggermont AMM, Franklin HR, Hart AAM. Patient and treatment related factors associated with acute regional toxicity after isolated perfusion for melanoma of the extremities. Am f Surg 1994, 167, 618620 .

17. Kroon BBR, Klasse JM, Geel van AN, Eggermont AMM. Application of hyperthermia in regional isolated perfusion for melanoma of the limbs. Reg Cancer Treat 1992, 4, 223-226.

18. Cavaliere R, DiFilippo F, Cavaliere F, et al. Clinical practice of hyperthermic extremity perfusion in combination with radiotherapy and chemotherapy. In Seegenschmiedt $M H$, Fessenden
P, Vernon CC, eds. Medical Radiology, Thermoradiotherapy and Thermochemotherapy, vol. II. Berlin, Springer-Verlag, 1996, 323-345.

19. Kroon BBR, Klaase JM, Merwe van de SA, Dongen van JA, Zee van der J. Results of a double perfusion schedule using high-dose hyperthermia and Melphalan sequentially for recurrent melanoma of the limbs: a pilot study. Reg Cancer Treat 1992, 4, 305-308.

20. Kroon BBR, Geel van AN, Benckhuijsen C, Wieberdink J. Normothermic isolation perfusion with Melphalan for advanced melanoma of the limbs. Anticancer Res 1987, 7, 441442.

21. Rosin RD, Westbury G. Isolated limb perfusion for malignant melanoma. Practitioner 1980, 244, 1031-1036.

22. Lejeune FJ, Deloof $T$, Ewalenko P. Objective regression of unexcised melanoma in transit metastasis after hyperthermia isolation perfusion of the limbs with Melphalan. Recent Res Cancer Res 1983, 86, 276-286.

23. Storm FK, Morton DL. Value of therapeutic hyperthermic limb perfusion in advanced recurrent melanoma of the lower extremity. Am f Surg 1985, 150, 32-35.

24. Di Filippo F, Calabro A, Giannarelli D, et al. Prognostic variables in recurrent limb melanoma treated with hyperthermic antiblastic perfusion. Cancer 1989, 63, 2551-2561.

25. Kroon BBR, Klaase JM, Geel van AN, Eggermont AMM, Franklin HR, Dongen van JA. Results of a double perfusion schedule with Melphalan in patients with melanoma of the lower limb. Eur f Cancer 1993, 29A, 325-328.

26. Klaase JM, Kroon BBR, Eggermont AMM, et al. A retrospective comparative study cvaluating the results of 'mild' hyperthermic versus 'controlled' normothermic perfusion for recurrent melanoma of the extremities. Eur $\mathcal{f}$ Cancer 1995, 31A, $58-63$.

27. Law MP, Ahier RG, Field SB. The response of the mouse ear to heat applied alone or combined with $\mathrm{X}$ rays. $B \mathcal{F}$ Radiol $1978,51,132-138$.

28. Haveman J, Jansen W, Wondergem J, Begg A. Cell proliferation in the murine epidermis and subcutaneous vascular endothelium after hyperthermia. Int $\mathcal{F}$ Radiat Biol 1988, 54, 105113.

29. Moritz AR, Henriques FC. Studies of thermal injury II. The relative importance of time and surface temperature in the causation of cutaneous burns. Am f Pathol 1947, 23, 695-720.

30. Meshorer A, Prionas SD, Fajardo LF, Meyer JL, Hahn GM, Martinez AA. The effects of hyperthermia on normal mesenchymal tissues. Arch Pathol Lab Med 1983, 107, 328-334.

31. Adams WM, Higgins PD, Siegfried L, Paliwal BR, Steeves RA. Chronic response of normal porcine fat and muscle to focused ultrasound hyperthermia. Radiat Res 1985, 104, 140-152.

32. Hoogeveen JF, Troost D, Kracht van der AHW, Wondergem J, Haveman J, Gonzalez Gonzalez D. Ultrastructural changes in the rat sciatic nerve after local hyperthermia. Int $f$ Hyperthermia 1993, 9, 723-730.

33. Wondergem J, Haveman J, Rusman V, Sminia P, Dijk van JDP. Effects of local hyperthermia on the motor function of the rat sciatic nerve. Int $\mathcal{F}$ Radiat Biol 1988, 53, 429-438.

34. Vujaskovic Z, McChesney Gillette S, Powers BE, et al. Effects of intraoperative hyperthermia on peripheral nerves: neurological and electrophysiological studies. Int $\mathcal{f}$ Hyperthermia $1994,10,41-49$.

35. Vujaskovic Z, McChesney Gillette $S$, Powers BE, et al. Effects of intraoperative hyperthermia on canine sciatic nerve: histopathologic and morphometric studies. Int $\mathcal{f}$ Hyperthermia $1994,10,845-855$.

36. Levine S, Mandelbrot A, Eidnoff $\mathrm{H}$. Thermal injury and induced thermotolerance in rat lymph nodes. Lymphology $1985,18,46-52$

37. Cavaliere R, Ciocatto EC, Giovanella BC, et al. Selective heat sensitivity of cancer cells. Biochemical and clinical studies. Cancer 1967, 20, 1351-1381.

38. Sapareto SA, Dewey WC. Thermal dose determination in cancer therapy. Int f Radiat Oncol Biol Phys 1984, 10, 787-800. 